\title{
QUEEN'S
UNIVERSITY
BELFAST
}

\section{The influence of assembly friction stir weld location on wing panel static strength}

Murphy, A., Ekmekyapar, T., Quinn, D., Özakça, M., Poston, K., Moore, G., \& Niblock, J. (2014). The influence of assembly friction stir weld location on wing panel static strength. Thin-Walled Structures, 76, 56-64. https://doi.org/10.1016/j.tws.2013.11.004

\section{Published in:}

Thin-Walled Structures

\section{Document Version:}

Peer reviewed version

\section{Queen's University Belfast - Research Portal:}

Link to publication record in Queen's University Belfast Research Portal

\section{Publisher rights}

NOTICE: this is the author's version of a work that was accepted for publication in Thin-Walled Structures. Changes resulting from the publishing process, such as peer review, editing, corrections, structural formatting, and other quality control mechanisms may not be reflected in this document. Changes may have been made to this work since it was submitted for publication.

\section{General rights}

Copyright for the publications made accessible via the Queen's University Belfast Research Portal is retained by the author(s) and / or other copyright owners and it is a condition of accessing these publications that users recognise and abide by the legal requirements associated with these rights.

Take down policy

The Research Portal is Queen's institutional repository that provides access to Queen's research output. Every effort has been made to ensure that content in the Research Portal does not infringe any person's rights, or applicable UK laws. If you discover content in the Research Portal that you believe breaches copyright or violates any law, please contact openaccess@qub.ac.uk. 


\title{
Buckling/Post-Buckling Strength of Friction Stir Welded Aircraft Stiffened Panels
}

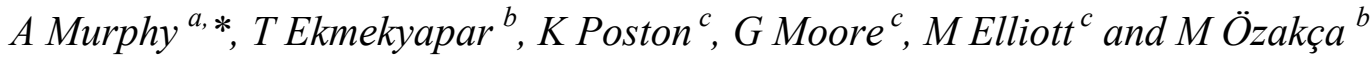 \\ ${ }^{a}$ School of Mechanical and Aerospace Engineering, Queen's University Belfast, \\ Ashby Building, Belfast. Northern Ireland, U.K. BT9 5 AH \\ ${ }^{b}$ Engineering Mechanics Division, University of Gaziantep, 27310 Gaziantep, Turkey \\ ${ }^{c}$ Bombardier Aerospace, Airport Road, Belfast, Northern Ireland, U.K. BT3 9DZ \\ *Corresponding author: Tel.: +442890974095; E-mail address: a.murphy@qub.ac.uk
}

\begin{abstract}
Assembling aircraft stiffened panels using Friction Stir Welding offers potential to reduce fabrication time in comparison to current mechanical fastener assembly, making it economically feasible to select structurally desirable stiffener pitching and novel panel configurations. With such a departure from the traditional fabrication process much research has been conducted on producing strong reliable welds, with less examination of the impact of welding process residual effects on panel structural behaviour and the development of appropriate design methods. This article significantly expands the available panel level compressive strength knowledge, demonstrating the strength potential of a welded aircraft panel with multiple lateral and longitudinal stiffener bays. An accompanying computational study has determined the most significant process residual effects that influence panel strength and the potential extent of panel degradation. The experimental results have also been used to validate a previously published design method, suggesting accurate predictions can be made if the conventional aerospace design methods are modified to acknowledge the welding altered panel properties.
\end{abstract}

\section{Keywords:}

Friction stir welding, stiffened panels, buckling analysis, post-buckling analysis. 


\subsection{Introduction}

To reduce the manufacturing cost and mass of aircraft aluminium stiffened panels significant research has been conducted on welding fabrication [1-17]. The key manufacturing challenges include the development of processing methods which robustly produce high quality joints but which do not significantly degrade the local material properties. Typically the aluminium alloys used in aircraft applications are heat treated to maximise static strength and thus the introduction of an intense localised heat source can degrade local joint material properties. This has focused research on the use of welding processes which concentrate heat input (e.g. Laser Beam Welding), or processes which work at lower temperatures than traditional fusion processes (e.g. Friction Stir Welding, FSW), and new aerospace weldable alloys [18]. The introduction of localised heat, the thermal conductivity of aluminium alloy and the thin-walled nature of aerospace stiffened panels make the task of minimising or controlling welding process residual panel distortion another major manufacturing challenge. Panel distortion arises due to the development of high transient thermal strains in the joint region during welding. When heat is applied compressive stresses are induced in the surrounding material due to thermal expansion. When the joint is formed and the cooling begins, the contraction of the local joint is resisted by the surrounding material creating tensile residual stresses. Some of the developed stress state may be relieved by the structure distorting, with the remaining stress state typically complex in nature. The optimisation of welding process parameters and the introduction of pre- and post-weld heat or mechanical treatments to minimise the final component distortion and residual stress state is key to the use of welding within the manufacture of aircraft thin-walled stiffened panels.

Major developments have been seen in all of the noted manufacturing challenges and the largest questions now occupy the themes of designing, analysing and verifying the generic 
use of welded aircraft stiffened panels. The herein work focuses on the static strength requirements of stiffened panels with this article aiming to demonstrate the compressive strength potential of a large scale welded aircraft panel with multiple lateral and longitudinal stiffener bays, verifying that the behaviour demonstrated during collapse is dominated by typical panel behaviour, and not by weld joint strength limitations. Such behaviour is required to maximise the strength to weight ratio of the panel structure. Having proved the large scale welded aircraft panel performance, detailed Finite Element simulation is then undertaken to determine the sensitivity of panel strength performance to varying levels of welding process residual effects. Finally, with the developed experimental data it is possible to validate a previously published analysis procedure for compressive strength, which to date has only been validated against small scale coupon experimental results [12].

\subsection{Background}

\section{$2.1 \quad$ Stiffened panels}

Stiffened panels dominate the wing, fuselage and empennage structure of aircraft. These are thin-walled structures, which exhibit structural instability when loaded in compression, potentially failing with stress levels lower than the material limits of their sub-components. The strength analysis of potentially unstable structures is dependent on component geometric dimensions, boundary conditions, load type, initial geometric and stress imperfections, as well as material properties. Thus stiffened panels are typically idealised as plate and column sub-components for compressive strength analysis [19]. For stiffened panels designed to operate in the post-buckled region, the panel skin may experience initial instability through localised skin segments buckling between lateral and longitudinal stiffeners. This initial buckling does not constitute panel failure as the panel can be designed to have the stiffeners 
carry additional loading until they become unstable and collapse. Moreover the support of the stiffeners enables a portion of the skin to carry load beyond the point of initial skin buckling, increasing the efficiency of the panel design. The ability to accurately predict the initial buckling, post-buckling and failure collapse behaviour of aircraft stiffened panels is therefore essential to aircraft design [20].

\subsection{Friction stir welding}

The key advantage of welding is the potential speed of the joining process when compared to riveting [1, 4-7]. In addition the removal of the vast majority of mechanical fasteners and the potential to select more structurally efficient stiffener pitching may enable reduced final panel weight. Although welding has many potential advantages the heat necessary for joining typically results in residual welding effects. The performance of thin-walled structures is potentially sensitive to these residual welding effects and therefore to minimise any impact FSW is of particular interest given its low processing temperatures. Lower welding temperatures can directly result in lower residual stress and distortion in fabricated panels, and reduced mechanical property degradation (in terms of ductility and strength [21]).

The FSW process is a solid state joining technique which uses local frictional heating to produce continuous solid-state seams. The process joins material by plasticizing and then consolidating the material around the weld line. A cylindrical, shouldered tool with a protruding pin is rotated and plunged into the components to be joined at the start of the weld line. The tool continues rotating and traverses forward in the direction of welding. Frictional heat is generated between the wear resistant tool and the component material. As the tool proceeds, the friction heats the surrounding material and rapidly produces a plasticized zone 
around the pin. This heat causes the local material to soften to a temperature below that of the material melting temperature and typically within the material's forging temperature range. As the tool moves forward metal flows to the back of the pin where it is extruded behind the tool. It then consolidates and cools to form the bond. To produce a lap joint, considered herein, the pin must extend a small amount through the bottom of the top component and into the bottom component. A schematic drawing of the lap joint welding process used herein is shown in Figure 1.

\subsection{Compressive strength of aerospace FSW panels}

FSW has been investigated as a rivet replacement technology for panel construction within spacecraft launch vehicles [3, 8]. Reduced length single-stiffener and full length multistiffener specimens have been tested under compression loading. The reduced length specimens have enabled weld joints to be loaded to extremely high compression stress levels. The welded single-stiffener specimens exhibited a higher average initial buckling load and a marginally lower average failure load than equivalent riveted specimens. In the case of the multi-stiffener specimens the welded specimen exhibited a lower failure load than the equivalent riveted specimen. These results emphasise the potential impact of welding process effects and the sensitivity of panel test performance to specimen scale.

FSW has also been investigated as a rivet replacement technology for fuselage manufacture $[13,14]$. Both reduced length single-stiffener and reduced length multi-stiffener specimens where tested under compression loading. In this work no equivalent riveted specimens were tested but an attempt was made to quantify the impact of welding process effects by Finite Element modelling of the experimental tests. The single-stiffener computational results determined that the level of material property degradation within the Heat Affected Zone 
(HAZ) and the welding induced residual stresses had the greatest influence on specimen collapse. The multi-stiffener computational results determined that the magnitude of welding induced residual stresses and associated geometric distortions had the greatest impact on initial skin buckling. Specimen collapse was determined to be most sensitive to the width of the weld joint, and the magnitude of the welding induced residual stresses. The reduced length multi-stiffener specimens allow a more realistic percentage volume of weld affected material compared to the single-stiffener specimens. However in both cases the specimen reduced length will have artificially modified the geometric imperfections and panel residual stresses.

FSW has also been investigated as an assembly method for the integrally stiffened panels found on the upper wing cover structure of commercial aircraft [16]. No experimental test data is presented but detailed Finite Element simulations demonstrate the potential impact of weld altered material properties on the maximum buckling load of the assembled wing structure.

Finally, modifications to conventional aircraft panel design methods have been proposed [12]. Single-stiffener specimen test results have established that standard panel buckling analysis procedures must be altered to account for the weld joint geometry and process altered material properties. However the proposed modifications have not been validated against full scale specimens with multiple lateral and longitudinal stiffener bays.

\subsection{Summary}

The FSW process induces complicated coupled thermal, mechanical and metallurgical behaviour resulting in residual effects within the fabricated panels. Results from both single 
stiffener and multi-stiffener aerospace specimen tests and coupled simulation studies have demonstrated that panel strength performance is influenced by the residual welding effects. To date no studies on the impact of welding process effects on full scale aerospace panel structures with multiple lateral and longitudinal stiffener bays is available in the literature. Moreover, as such experimental work is not available the modified strength analysis methods [12] for welded aircraft structures are as yet unvalidated for panel structure with multiple lateral and longitudinal stiffener bays.

\subsection{Experimental programme}

\subsection{Specimen design}

In order to fill the identified gap in experimental knowledge, a test programme was developed to demonstrate the strength potential of a sample welded aircraft fuselage panel with multiple lateral and longitudinal stiffener bays under uniform compression loading. To represent realistic aircraft structure a conventional panel design was created based on generic design requirements for a single aisle civil transport aircraft fuselage. An intermediate magnitude fuselage panel ultimate loading intensity was first specified (of the order of 450 $\mathrm{N} / \mathrm{mm}$ ) along with typical fuselage design constraints on plastic material behaviour and initial skin buckling. A series of standard aerospace minimum manufacturing, fatigue and damage tolerance requirements were also specified to ensure a realistic design. A test specimen configuration of five lateral stringer bays and three longitudinal frame bays was then developed from the representative panel design, Figure 2.

The resulting specimen design consisted of a constant thickness skin of typical fuselage skin material (AA2024), extruded Z-section longitudinal stringers, and press formed C-section 
lateral frames, both in a typical fuselage stiffener material (AA7075). The central three stringers were designed with a continuous weld joint to the skin via the lower wider Z-section flange, hereafter referred to as the attached flange. The two edge stringers, which were marginally oversized to promote specimen failure within the specimen central zone away from the specimen boundaries, where attached to the skin via standard aerospace countersunk fasteners, again with the aim of promoting specimen failure inside the specimen central zone. The specimen lateral frames were also attached to the skin via counter-sunk fasteners and at each stringer-frame intersection a stringer opening was designed to allow the uninterrupted passage of the stringers. Cleats (AA2024) where also attached at each stringerframe intersection, designed to offer the stringers additional support against instability [22].

Given the scale of the specimen design and the resulting cost of manufacture and test no repeat tests were possible. Previous dual specimen tests of large riveted panel specimens, with multiple lateral and longitudinal stiffener bays have produced collapse loads within $2.75 \%$ under uniform compression loading [20]. The repeatability of assembled geometry is a key target of automated FSW panel assembly and a potential advantage over manual fastener assembly.

\subsection{Specimen manufacture}

The specimen skin was initially cut to size in the width but cut marginally over sized in the length (i.e. in the loading direction). The central stringers were also cut marginally over sized and welded to the skin with continuous flange lap welds. Once welded the skin-stringer structure was inspected before the lateral frames and edge stringers were attached. Once fabricated the specimen ends were cast in epoxy tooling resin and machined parallel, allowing simultaneously the uniform compression loading of the specimen and clamped 
loading edge boundary conditions. Applying clamped boundary conditions at the specimen loading ends, stabilises the upper and lower specimen frame bays, thereby again promoting failure of the specimen within its central zone.

\subsection{Specimen test}

The specimen was tested in a $1,500 \mathrm{kN}$ capacity hydraulic testing machine. Two edge guides, fixed to the lower loading platen were slotted onto the free flanges of the edge stringers. These support members were designed to stop out-of-plane deformation of the edge stringer free flanges during testing, stabilising the edge stringers and promoting failure to occur in the specimen central zone. An end-shortening gap was designed between the top of the edge guides and the upper loading platen. In order to support the specimen lateral frames from outof-plane deflection during test, a series of horizontal tie rods connected each frame to remote lateral anchor points. The specimen was strain gauged with gauge locations selected to enable the definition of initial specimen buckling and post-buckling collapse behaviour. Specimen end-shortening was measured during test using calibrated displacement transducers. The specimen was loaded monotonically, in displacement control, at a rate of $0.25 \mathrm{~mm}$ per minute until failure occurred. Load, deflection and strain data were recorded at set load intervals during test.

\subsection{Supplementary tests}

A series of supplementary measurements and tests were also undertaken to determine the impact of welding on the final fabricated test specimen. Micro hardness mapping was undertaken on a series of weld cross-section coupons, sectioned from equivalent specimen joints. Using the generated hardness data and semi-empirical models, similar to those developed by Myhr \& Grong [23], the weld joint material properties were calculated. In order 
to understand the residual stress magnitudes present within the specimen a series of measurements via the hole-drilling method [24] were performed on similar scale specimens which were fabricated from the same batch materials and using the same welding process parameters.

In addition material tests were undertaken to determine the batch material properties for each of the specimen skin, stringer and frame sub-components. These material tests were preformed in accordance with the ASTM compressive material testing standards [25]. Post test the captured material property data was processed for use within Finite Element simulations, in addition the data was fitted with the Ramberg-Osgood parameters [26] thus enabling its use with standard aerospace strength analysis methods [19, 28-29].

\subsection{Sensitivity study}

Based on the experimental test programme outlined in Section 3 an accompanying Finite Element (FE) simulation programme was undertaken. First, a FE simulation was created to model the behaviour of the experimental specimen, modelling the measured welding process residual effects. The ability of this simulation to predict the specimen's initial buckling and collapse behaviour was then assessed against the measured test results. Having validated the prediction capability of the simulation the modelled welding process residual effects were then systematically varied with a Design Of Experiment (DOE) simulation series to identify the key process effects which impact strength. Having identified the key process effects a series of parametric simulation studies were then completed to understand the detailed nature of the relationship between the magnitude of the key welding effects and specimen initial buckling and collapse performance. 


\subsection{Simulation procedure}

Using the FE method and employing non-linear material and geometric analysis procedures previous research has shown that the compressive strength performance of stiffened panels with welding process residual effects can be simulated $[12,14]$. Previous work has concluded that to represent the typical buckling failure modes of a stiffened panel the structure must be idealised as an assemblage of inter-connected shells, with the stiffener web and flanges, along with the panel skin components represented with shell elements. In addition, the stiffenerskin joints must be accurately represented with the weld connection along with any contact conditions between the stiffener and skin modelled [9]. Based on this preceding knowledge Figure 3 outlines the mid-plane shell element representation of the experimental compression test specimen. Figure 3 also outlines the local stiffener-skin joint idealisation, where the skin and stiffener attached flange nodes in the weld joint zone are connected via rigid link elements, and the skin and stiffener attached flange nodes outside the weld joint zone are connected via uni-axial contact elements.

Applying the element selection and mesh convergence procedures outlined in Murphy et al. [30] a 4-node shell element with 6 degrees of freedom at each node (ANSYS element SHELL181) was selected to represent all panel skin and stiffener components. With the selected element, the convergence study defined a minimum mesh density of twelve nodes per buckle half wave for the panel skin segments. The final mesh for each analysis was defined considering the minimum mesh density and the desire to have a consistent mesh pattern across the complete simulation programme, Figure 3. 
The loading and boundary conditions applied to the model were designed to represent the experimental test setup outlined in Section 3.3. To model the test specimen ends, the out-ofplane displacements of the nodes within the panel zones that were cast in epoxy resin in the experimental tests were restrained. To represent specimen loading, a uniform axial displacement was applied to the lower end of the model, while the axial displacement at the opposite end was restrained, again in the axial direction. The edge stringer free flanges constrained within the edge guides where constrained from out-of-plane displacements, again corresponding with the experimental setup. Finally, to represent the combined effect of the lateral specimen frames along with their tie rod connection to remote anchor points, simplesupport conditions where applied to the model skin nodes across the specimen width at the frame fastener centre line planes.

Stress-strain curves obtained from the material tests outlined in Section 3.4 were incorporated into a multi-linear isotropic strain hardening material model available within the FE simulation software. For the computational analysis a displacement controlled incrementaliterative Newton-Raphson solution procedure was used [27]. To determine initial skin buckling the average strain method was used [31], both in the experimental and computational analysis, therefore allowing direct comparison of the results. The method plots the load against the mid-plane strain at the centre of the skin bay, with buckling defined to have occurred when a sharp break is seen in the data. The strain data used for each experimental and computational calculation was taken from the same central specimen skin bay. For ultimate collapse load definition, the maximum experimental or computational load carried by the specimen was used. 


\subsection{Welding process residual effects}

Based on the previous research on friction stir lap welding [12, 14, 32-36] a total of five welding process residual effects were identified for inclusion within the FE simulation programme:

a) The width of the effective weld joint ( $\left.\mathrm{w}_{\text {weld }}\right)$, Figure 3.

b) The location of the effective weld joint centre $\left(\mathrm{w}_{\mathrm{cl}}\right)$, Figure 3.

c) The effective strength of the HAZ material $\left(\mathrm{k}_{\mathrm{z}}\right)$ - this factor relates the degraded strength of the HAZ material to the original parent material strength, $\mathrm{k}_{\mathrm{z}}$ being equal to the ratio of HAZ material proof stress to parent material proof stress.

d) The width of the HAZ (z), Figure 3.

e) The tensile magnitude of welding induced residual stress $\left(F_{r s}\right)$. Herein the welding induced residual stress state is simply idealised as a uniform tensile stress region at each weld joint with equalising compression stress within the extended panel structure. The magnitude of residual stress is defined using the tensile stress, expressed as a percentage of the original parent material proof stress.

Table 1 summarises the range of welding process effect magnitudes under consideration. The selected magnitudes represent generic bounding values based on typical fuselage materials and joint geometries, with minimum degrading magnitudes intended to represent optimised welding parameters and pre- or post-weld heat or mechanical treatments, with maximum degrading magnitudes designed to represent non-optimised welding parameters with no preor post-weld heat or mechanical treatments.

\subsection{Modelling welding residual effects}


The inclusion of the degraded material properties in the HAZ was achieved by modelling the shell element properties within the specimen zones within the HAZ width with HAZ material properties obtained from the supplementary experimental tests outlined in Section 3.4. The remaining specimen zones where modelled with the parent material properties obtained from the coupon tests, again outlined in Section 3.4. Representing the location of the effective weld joint centre and joint width was achieved by modelling the correct combination of rigid link and uni-axial contact elements between the relevant skin and stiffener attached flange nodes along each welded skin-stringer joint line, Figure 3.

The inclusion of the welding induced residual stress within the computational simulations required a three-step analysis:

- $I^{\text {st }}$ analysis step - The post weld residual stress state is initially idealised as a uniform tensile zone centred on each of the specimen's skin-stringer weld lines and an initially uniform equalising compression zone elsewhere within the model. The perfect mesh of the test specimen, without edge stringers or frames, is modelled with the idealised post weld residual stress state and with minimum boundary conditions to prevent rigid body translations or rotations. This step represents the unclamping of the welded skin and stringers from their fixturing required for the welding process [37-38]. When the residual stresses are introduced to the model, the structure is no longer in equilibrium, and a nonlinear geometric analysis is carried out to establish static equilibrium. The equilibrium calculation generates a distorted structure, and a slightly modified stress state.

- $2^{\text {nd }}$ analysis step - Having created an imperfect initial geometry and stress model for the skin and three central welded stringers a second simulation stage is completed to represent the mechanical fastener attachment of the specimen frames and edge stringers. The stressed and deformed mesh of the $1^{\text {st }}$ analysis step has the skin nodes along the edge 
stringer and frame fastener centre lines displaced to a zero out-of-plane location and the absent stiffeners then added to the model, and a non-linear geometric analysis carried out to establish static equilibrium. Note the absent stiffener geometry is modelled through-out the analysis but in the preceding step their material stiffness is modelled at a fraction of the true value, and in the $2^{\text {nd }}$ and $3^{\text {rd }}$ analysis step the true material stiffness is represented.

- $3^{\text {rd }}$ analysis step - Having created an imperfect specimen geometry and stress state which represents the specimen manufacturing process the third analysis describes the specimen compression testing. The analysis starts with the stressed and deformed mesh produced by the $2^{\text {nd }}$ analysis step and the test loads and boundary conditions described previously, Section 4.1, are applied to the imperfect specimen model to predict the specimen behaviour under test.

Figure 4 presents the stress imperfection and Figure 5 the geometric imperfection generated by each step undertaken to create an imperfect specimen model.

\subsection{Identification of key welding process residual effects}

Examining the five identified residual effects potentially requires significant computational effort. Considering a full factorial simulation series examining each effect at three independent levels would require a total of $5^{3}$ or 125 simulations. Given this potential computational expense a fractional factorial approach, the Taguchi method [39], is used herein to govern the simulations. In this method a special orthogonal array is used to define a simulation series such that the understanding of the individual and combined influence of input factors (in this case the welding process residual effects) on the output results (the specimen strength performance) is achieved from a minimum number of simulations. In order 
to determine the most appropriate combination of interactions to be studied an initial lower fidelity simulation series was first formulated with interactions selected based on heuristic FSW process knowledge. The results were then processed and the residual effects ranked. A modified simulation series was then formed which amended the studied interactions such that all combinations of interactions between dominant residual effects were calculable. Table 2 presents the final two-level orthogonal array used to study the five selected welding process residual effects and the dominant residual effect interactions.

Based on the simulation series an ANalysis Of VAriance (ANOVA) was preformed on the predicted initial skin buckling and ultimate collapse loads allowing the influence of each residual effect to be numerically characterised. Table 5 presents both the initial unpooled and pooled ANOVA results. The pooling strategy entailed F-testing between effects with the most insignificant effects pooled into the unidentified contribution. In addition student's $t$ tests (alpha $=0.05, \mathrm{t}=2.17881$ ) where used to confirm for each significant effect that the output means (either initial skin buckling or collapse load) are significantly different at the two effect levels.

\subsection{Parametric study of key welding process residual effects}

As the results from a fractional factorial simulation series are influenced by the range of effect magnitudes analysed, a series of additional simulations were performed to confirm and define the form of the key relationships. The studied effect magnitude ranges were based on the identified boundaries outlined in Table 1. During the parametric studies the non-varying process effects were set to represent the experimental specimen measured effect magnitudes, also outlined in Table 1. 


\subsection{Results}

This section presents the results of the experimental and computational work detailed in Section 3 and 4.

\subsection{Experimental results}

Table 3 presents the measured specimen initial buckling and collapse performance. The test specimen performed as designed, with initial buckling and ultimate failure occurring within the central zone of the specimen. The specimen failed at $336.8 \mathrm{kN}$ by combined stiffener global flexure and local free flange instability, Figure 6. Prior to ultimate failure initial skin bay buckling occurred at 27 per cent of the ultimate test load. Weld joint integrity was maintained throughout initial skin buckling, post-buckling and overall specimen collapse, demonstrating the strength potential of welded aircraft panels with multiple lateral and longitudinal stiffener bays. The demonstrated behaviour during test was dominated by typical panel stability with the strength of the local weld joints not limiting performance.

\subsection{Baseline simulation results}

Table 3 presents the predicted specimen initial buckling and collapse performance when the test specimen residual effect magnitudes are represented within the model, Table 2. Specimen failure is predicted to occur at $342.2 \mathrm{kN}$ by combined stiffener global flexure and local free flange instability, and initial skin buckling is predicted to occur at $91.0 \mathrm{kN}$. The simulation thus marginally over-predicts the load to cause initial skin buckling by 1.4 per cent and the collapse load by 1.6 per cent, correctly predicting the mode of collapse. Clearly the accuracy of the simulation prediction is very high and thus appropriate for further analysis on the influence of the welding residual process effects. 
For completeness a 'perfect' baseline simulation was also analysed, representing the test specimen weld joint width and location but with zero material property degradation and welding induced residual stress $\left(\mathrm{w}_{\mathrm{w} \text { eld }}=\mathrm{t}_{\mathrm{af}}, \mathrm{w}_{\mathrm{cl}}=-\mathrm{t}_{\mathrm{af}}, \mathrm{k}_{\mathrm{z}}=1.0, \mathrm{z}=0, \mathrm{~F}_{\mathrm{rs}}=0 \%\right)$. This enables an estimation of the total impact of the specimen material property degradation and welding induced residual stress on specimen strength. Specimen initial skin buckling was predicted to occur at $96.5 \mathrm{kN}$ (6.0 per cent higher than the test specimen simulation). The 'perfect' baseline simulation predicted specimen collapse to occur at $352.7 \mathrm{kN}$ by combined stiffener global flexure and local free flange instability, the same failure mode as the test specimen simulation, but at a 3.1 per cent higher load.

\subsection{Fractional factorial simulation series}

\subsubsection{Initial skin buckling}

The results of the fractional factorial simulation series defined in Table 2 are presented in Table 4. Examining the results from the sixteen simulations the maximum variation in predicted initial skin buckling load is 19.0 per cent $(17.1 \mathrm{kN})$. The outcome of the ANOVA analysis, Table 5, establishes that the dominant factor influencing initial skin buckling is the location of the effective weld joint centre with an individual contribution of 54.9 per cent. The width of the effective weld joint is determined to have the second greatest influence on initial skin buckling, with an individual contribution of 21.5 per cent. Thus the weld joint characteristics have a significant impact on skin buckling. This is potentially not surprising as the weld joints define the lateral width of the central specimen skin bays and significantly influence the skin bay boundary conditions, effectively defining the rotational constraint provided by the stringers. 
The ANOVA analysis also identifies the tensile magnitude of welding induced residual stress as the third most significant effect on initial buckling (16.6 per cent). Understandably the tensile residual stress will impact on the magnitude of the initial specimen geometric imperfection and this along with the compressive residual stresses in the skin will impact on stability behaviour. The ANOVA analysis identifies that the strength of the HAZ material and the width of the HAZ have no significant influence on initial skin buckling. This is confirmed by examining the specimen stress levels at initial buckling, which are all within the elastic material range.

\subsubsection{Collapse}

Considering the results of the sixteen simulations, Table 4, the maximum variation in simulated specimen collapse load is 8 per cent $(26.7 \mathrm{kN})$. This prediction range suggests that the collapse performance of the specimen is less sensitive to the weld effects and the range of magnitudes examined than initial skin buckling. All sixteen simulations experience specimen failure within the central zone, with a combined stiffener global flexure and local free flange instability mode. Figure 7 depicts the load versus end-shortening curves for the maximum (simulation number 1, Table 4) and minimum (simulation number 10) collapse load predictions.

The bounding simulations (number 1 and 10) predicted collapse loads both compare well with the test results. Both simulations predict the same axial stiffness up to initial skin buckling. Beyond this region the curves diverge and the higher post-buckling axial stiffness of simulation 10 leads ultimately to a higher collapse load. The collapse modes of the two bounding simulations are also presented in Figure 7, where marginal differences in mode peak location and form can be observed. 
The collapse ANOVA analysis reveals that the two dominant effects on specimen performance are the tensile magnitude of welding induced residual stress and the location of the effective weld joint centre, with individual contributions of 31.0 per cent and 11.9 per cent respectively, Table 5. The ANOVA analysis also identifies a significant level of interaction between the location of the effective weld joint centre and the width of the effective weld joint (25.3 per cent).

The ANOVA analysis again identifies that the strength of the HAZ material and the width of the HAZ have no significant influence on specimen collapse. This is confirmed by examining the specimen local stress levels at collapse, which are within the initial plastic material range. Finally it is worth noting the significant magnitude of unidentified percentage contributions within the ANOVA collapse analysis (31.8 per cent in total). This reflects the complication of the post-buckling collapse analysis and confirms the need for a second phase parametric examination of the key effects, which is presented next.

\subsection{Parametric study}

The ANOVA analysis identifies three significant effects, namely the width of the effective weld joint, the location of the effective weld joint centre, and the tensile residual stress, which impact specimen initial buckling and collapse performance, Table 5. Of these identified effects the tensile residual stress is potentially the most difficult to control, whereas the location of the effective weld joint centre may be manipulated through the selection of welding process parameters [32-33] and welding direction (as a single pass FSW joint is not symmetric with respect to the seam line due to the rotation of the tool). The width of the effective weld joint can also be effectively manipulated via the design of the welding tool and 
process parameters $[32-33,40]$. Therefore in the parameter study a single discrete weld joint configuration has been studied, representing the mean of the physical joint characteristics under consideration $\left(\mathrm{w}_{\mathrm{w} e l d}=2 \mathrm{t}_{\mathrm{af}}\right.$ and $\left.\mathrm{w}_{\mathrm{cl}}=0\right)$. However, given the challenge of controlling residual stress the magnitude of the welding induced residual stress has been examined in detail at seven individual magnitudes $(5 \%, 10 \%, 20 \%, 30 \%, 40 \%, 50 \%$ and $60 \%$ of the original parent material proof stress).

\subsubsection{Initial skin buckling}

The specimen initial skin buckling modes and loads for the parametric results are presented in Figure 8. Examining the results it can be seen that the buckling load decreases continuously with higher magnitudes of initial residual stress. There is an approximately linear relationship between the magnitude of welding induced residual stress and the buckling performance (a reduction of $89 \mathrm{~N}$ for each per cent increase in stress magnitude). Across the simulation series there is only small deviations in the predicted skin buckling wave forms, however as the residual stress is increased specimen lateral edge bay buckles become more visible, Figure 8 .

\subsubsection{Collapse}

Figure 9 presents the collapse results of the parametric study. Examining the results it can be seen that there is only a very slight variation in the specimen collapse load with varying magnitudes of initial residual stress. No simple relationship is visible between the magnitude of initial residual stress and the collapse performance. Across the simulation series the maximum variation in simulated specimen collapse load is 3.3 per cent $(10.9 \mathrm{kN})$. The variation present is visible in the predicted collapse modes, Figure 9, with small deviations in the ultimate buckling wave modes (with all simulations predicting central specimen failure, occurring by combined stiffener global flexure and local free flange instability). 


\subsection{Summary}

The experimental work has demonstrated the potential strength of panel stiffener to skin joints under large panel buckling collapse behaviour, with weld joint integrity maintained through initial skin buckling, post-buckling, and ultimate panel collapse. The numerical simulations achieved excellent agreement with the specimen test behaviour and the results of the fractional factorial simulation series and ANOVA analysis determined the dominant effects influencing specimen strength as the width of the effective weld joint, the location of the effective weld joint centre, and the tensile residual stress. Overall the ANOVA computational analysis determined a relatively modest impact on strength for the full scale panel specimen examined and the effect magnitude ranges analysed (19 per cent for initial skin buckling and 8 per cent for collapse load). The parametric computational analysis confirmed the initial ANOVA findings and defined an approximately linear relationship between the magnitude of welding induced residual stress and the initial skin buckling performance.

\subsection{Modified strength design method}

As noted in the background section previous work [12] has proposed modifications to conventional aircraft panel analysis methods [19, 28-29] to acknowledge welding altered panel properties. To examine the accuracy of the previously published method on larger welded panel structures the 'fully factored' analysis method outlined in reference 12 was performed on the current specimen. Table 3 presents the analysis results. 
The predicted specimen performance was reasonably close to the experimental results, with the initial buckling behaviour marginally under predicted $(-3.8$ per cent). In the case of collapse performance the under prediction was larger, -12.8 per cent, with the correct specimen failure mode predicted. The accuracy of these predictions is considered good given that the basic conventional analysis methods, into which the modifications are incorporated, contain empirical data and conservative simplifying assumptions which generally weaken accuracy [20]. In addition, the modified methods do not account for welding induced residual stresses or welding specific distortions.

\subsection{Conclusions}

Despite considerable developments on the manufacturing challenges associated with aircraft stiffened panel FSW assembly; significant questions remain with respect to compressive strength performance and design and analysis methods. To date studies have focused at smaller scale test specimens but herein a large scale welded aircraft panel with multiple lateral and longitudinal stiffener bays has been tested, verifying that the panel behaviour is not limited by weld joint failure. Moreover detailed FE simulations have determined the dominant effects influencing large scale panel strength as the width and location of the effective weld joint, and the tensile residual stress. However in general the computational analysis demonstrates the relatively modest impact that welding effects have on the strength of full scale panel structure, significantly lower than that demonstrated in preceding work on smaller panel specimens. Critically reviewing the herein work it is important to note that the residual stress distribution modelled within the FE simulations is a highly idealised representation of the initial stress state due to welding. The seeded stress state does not consider other prior part production stresses, such as skin rolling or stiffener extrusion. Given 
the determined importance of the initial stress state a potential theme for future investigation is the sensitivity of residual stress idealisation on predicted panel buckling and collapse behaviour.

In addition, a previously published strength analysis method has been validated on the large scale test specimen results, indicating accurate predictions are possible with simple hand calculations if the analysis methods acknowledge the altered panel properties. Such simple design methods are appropriate to initially size panel structure in which compression is the dominant load, however further investigation is required to expand the approach to the sizing of panels dominated by multi-axial loading.

The experimental demonstration of normal buckling and collapse behaviour in a large panel structure, and the new understanding of panel strength sensitivity to welding process effects, combines to represent a significant step towards FSW assembled aircraft fuselages.

\section{Acknowledgements}

The authors gratefully acknowledge the technical and financial support of Bombardier Aerospace Shorts. Additional financial support from The Scientific and Technological Research Council of Turkey (TUBITAK), under the Science Fellowships and Grant Programmes Department (BIDEB) is also gratefully acknowledged. 


\section{References}

[1] Zink, W., "Advanced Aircraft Fuselage Structures", The European Symposium on Assessment of Power Beam Welds. GKSS Research Centre, Geesthact, Germany, 1999.

[2] Gibson, A., and Sterling, S., "A design and test programme involving welded sheetstringer compression panels", 21st International Council of the Aeronautical Sciences Congress, Melbourne, Australia, ICAS-98-7.7.4, 1998.

[3] Dracup, B.J. and Arbegast, W.J., "Friction Stir Welding as a Rivet Replacement Technology", Proceedings of the 1999 SAE Aerospace Automated Fastening Conference \& Exposition, Memphis, TN, October 5-7, 1999.

[4] Zink, W, "Laser beam welding for aircraft structures", Aeromat 2000, Daimler Chrysler Aerospace Airbus, Bremen, 2000.

[5] Irving, P., "End of the aircraft rivet-the coming of the welded aircraft", Aerogram, Vol. 10, No. 2, September 2001.

[6] Mendez, P.F., and Eagar, T.W., "Welding Processes for Aeronautics", Advanced Materials \& Processes, pp 39-43, May 2001.

[7] Zink, W., "Welding fuselage shells, Industrial Laser Solutions”, April 2001.

[8] Hoffman, E.K., Hafley, R.A., Wagner, J.A., Jegley, D.C., Pecquet, R.W., Blum, C.M. and Arbegast, W.J., "Compression Buckling Behaviour of Large-Scale Friction Stir Welded and Riveted 2090-T83 Al-Li Alloy Skin-Stiffener Panels”, NASA/TM-2002211770, NASA Washington, DC, August 2002.

[9] Murphy, A., Lynch, F., Price, M., and Wang, P., "The Static Strength Analysis of Friction Stir Welded Stiffened Panels for Primary Fuselage Structure”, ICAS 2004, Yokohama, August 2004, ICAS-2004-5.6.3.

[10] Zhang, X. and Li, Y., "Damage Tolerance and Fail Safety of Welded Aircraft Wing Panels", AIAA JOURNAL, Vol. 43, No. 7, July 2005 
[11] Lynch, F., Price, M., Murphy, A., Gibson, A., Poston, K. and Moore, G., “Analysis of Weld Configuration for Laser Welded Skin-Stringer Fuselage Sub-Panels in Compression", 4th International Conference on Thin-Walled Structures, Loughborough, England, pp. 145-152, 2004.

[12] Murphy A., Lynch F., Price M., and Gibson A., "Modified stiffened panel analysis methods for laser beam and friction stir welded aircraft panels”, Proc. Inst. Mech. Eng. Part G-J. Aerosp. Eng., 220 (2006) 267-278.

[13] Murphy, A., Price, M., Curran, R. and Wang, P., "The Integration Of Strength And Process Modeling Of Friction-Stir-Welded Fuselage Panels", AIAA Journal of Aerospace Computing, Information, and Communication, Vol. 3, pp 159-176, 2006.

[14] Murphy A., McCune W., Quinn D., and Price M., "The characterisation of friction stir welding process effects on stiffened panel buckling performance”, Thin-Walled Struct., 45 (2007) 339-351.

[15] Widener, C., Tweedy, B., and Burford, D., "Path Independence of Allowables Based Friction Stir Butt Welds", 7th AIAA Aviation Technology, Integration and Operations Conference (ATIO), AIAA 2007-7864, Belfast, Northern Ireland, 2007.

[16] Yoon J.W., Bray G.H., Valente R.A.F., and Childs T.E.R., "Buckling analysis for an integrally stiffened panel structure with a friction stir weld”, Thin-Walled Structures 47 (12) (2009), pp. 1608-1622

[17] Serroni G., Squillace A., Prisco U., Bitondo C., and Prisco A., "Aircraft panels stiffened by friction stir welded extruded parts: mechanical characterization”, La Metallurgia Italiana, No. 1, 2011, pp. 35-39.

[18] Lequeu Ph., Muzzolini R., Ehrstrom J.C., Bron F., and Maziarz R., "High-Performance Friction Stir Welded Structures Using Advanced Alloys”, The 17th Advanced 
Aerospace Materials \& Processes Conference and Exposition (AeroMat 2007), May 2006, Seattle, USA.

[19] Bruhn, E.F., "Analysis and design of flight vehicle structures", 1st edition, Tri-State Offset Company, 1973.

[20] Lynch, C., Murphy, A., Price, M. and Gibson, A., "The computational post buckling analysis of fuselage stiffened panels loaded in compression", Thin-Walled Structures, Vol. 42:10, pp 1445-1464, 2004.

[21] Cavaliere P., Nobile R., Panella F.W., Squillace A., "Mechanical and microstructural behaviour of 2024-7075 aluminium alloy sheets joined by friction stir welding", International Journal of Machine Tools and Manufacture, 46 (2006) 588-594.

[22] Cutler, J., "Understanding aircraft structures", Blackwell Science, Oxford, 2005 (ISBN: 0-632-05001-2).

[23] Myhr, O.R. and O.Grong, "Process modelling applied to 6082-T6 aluminium weldments - ii. application of model", Acta Metallurgica et Materialia, Vol. 39(11), pp. 2703-2708, 1991.

[24] Anon., "Standard Test Method for Determining Residual Stresses by the Hole-Drilling Strain-Gage Method", American Society for Testing and Materials, ASTM E837-08, 2008

[25] Anon., "Standard test methods of compression testing of metallic material at room temperature", American Society for Testing and Materials, ASTM E9-89a, 1989.

[26] Ramberg, W., and Osgood, W.R., "Description of Stress-Strain Curves by Three Parameters", National Advisory Committee of Aeronautics, Washington, USA, 1943.

[27] Becker, A.A., "Understanding non-linear finite element analysis - Through illustrative benchmarks", 1st edition, NAFEMS (ISBN 1-8743-7635-2), 2001. 
[28] Anon., "NASA Astronautics Structures Manual, Vol. 3", NASA, Washington, US, 1961.

[29] Anon., "ESDU Structures sub-series", Engineering sciences data units, ESDU International Ltd, London, 1965.

[30] Murphy, A., Price, M., and Gibson, A., "Toward virtual testing of airframe stiffened panels”, Royal Aeronautical Society - Virtual Testing Conference, London, 2006.

[31] Singer J, Arbocz J, and Weller T., "Buckling experiments: Experimental methods in buckling of thin-walled structures”, 1st edition, John Wiley \& Son, 1997.

[32] Cederqvist L., and Reynolds A.P., "Factors affecting the properties of friction stir welded aluminum lap joints", Weld J 80 (12) (2001), pp. 281-287.

[33] Dubourga L., Meratib A., and Jahazic M., "Process optimisation and mechanical properties of friction stir lap welds of 7075-T6 stringers on 2024-T3 skin", Materials \& Design, Volume 31, Issue 7, August 2010, Pages 3324-3330.

[34] Brooker MJ, Van Deudekom AJ, Kallee SW, Sketchley PD., “Applying friction stir welding to the ariane 5 main motor thrust frame. In: European conference on spacecraft structures, materials and mechanical testing, Noordwijk, Netherlands, November 29December 1. European Space Agency; 2000, p. 507.

[35] Fersini D., and Pirondi A., "Fatigue behaviour of A12024-T3 friction stir welded lap joints", Engineering Fracture Mechanics, Vol. 74 (4), 2007, pp. 468-480.

[36] Ericsson M., Lai-Zhe J., and Sandstrom R., "Fatigue properties of friction stir overlap welds", International Journal Fatigue, Vol. 29 (1), 2007, pp. 57-68.

[37] Mishra R.S. and Ma Z.Y., "Friction Stir Welding and Processing”, Materials Science and Engineering R: Reports 50 (1-2) (2005), pp. 1-78.

[38] McCune R., Murphy A., Price M. and Butterfield J., "The influence of Friction Stir Welding process idealisation on residual stress and distortion predictions for future 
airframe assembly simulations", Journal of Manufacturing Science and Engineering, Volume 134, Issue 3, pp 031011, June 2012.

[39] Roy R., "A primer on the Taguchi method", Society of Manufacturing Engineers, Michigan, USA, 1990.

[40] Thomas WM, Johnson KI, and Wiesner CS, "Friction stir welding - Recent developments in tool and process technologies", Advanced Engineering Materials, Vol. 5(7), 2003, pp. 485-90. 
Table 1 - Test specimen welding process residual effect magnitudes plus fractional factorial analysis lower and upper boundary values.

\begin{tabular}{lccc}
\hline \multicolumn{1}{c}{ Welding process effect } & $\begin{array}{c}\text { Test } \\
\text { specimen }\end{array}$ & $\begin{array}{c}\text { Lower } \\
\text { boundary }\end{array}$ & $\begin{array}{c}\text { Upper } \\
\text { boundary }\end{array}$ \\
\hline Width of the effective weld joint $\left(\mathrm{w}_{\text {weld }}\right)$ & $\mathrm{t}_{\mathrm{af}}$ & $\mathrm{t}_{\mathrm{af}}$ & $3 \mathrm{t}_{\mathrm{af}}$ \\
Location of the effective weld joint centre $\left(\mathrm{w}_{\mathrm{cl}}\right)$ & $-\mathrm{t}_{\mathrm{af}}$ & $-\mathrm{t}_{\mathrm{af}}$ & $+\mathrm{t}_{\mathrm{af}}$ \\
$\begin{array}{l}\text { Effective strength of the HAZ material }\left(\mathrm{k}_{\mathrm{z}}\right) \\
\text { Width of the HAZ }(\mathrm{z})\end{array}$ & 0.8 & 0.7 & 0.9 \\
$\begin{array}{l}\text { Tensile magnitude of welding induced residual } \\
\text { stress }\left(\mathrm{F}_{\mathrm{rs}}\right)\end{array}$ & $60 \%$ & $20 \%$ & $60 \%$ \\
\hline
\end{tabular}

Table 2 - Fractional factorial simulation series.

\begin{tabular}{ccccccccc}
\hline $\begin{array}{c}\text { FE } \\
\text { simulation } \\
\text { number }\end{array}$ & $\mathrm{w}_{\mathrm{wweld}}$ & $\mathrm{w}_{\mathrm{cl}}$ & $\begin{array}{c}\text { Interaction } \\
\left(\mathrm{w}_{\text {weld }}\right) \times\left(\mathrm{w}_{\mathrm{cl}}\right)\end{array}$ & $\mathrm{k}_{\mathrm{z}}$ & $\mathrm{z}$ & $\mathrm{F}_{\mathrm{rs}}$ & $\begin{array}{c}\text { Interaction } \\
\left(\mathrm{w}_{\text {weld }}\right) \times\left(\mathrm{F}_{\mathrm{rs}}\right)\end{array}$ & $\begin{array}{c}\text { Interaction } \\
\left(\mathrm{w}_{\mathrm{cl}}\right) \times\left(\mathrm{F}_{\mathrm{rs}}\right)\end{array}$ \\
\hline 1 & $\mathrm{t}_{\mathrm{af}}$ & $-\mathrm{t}_{\mathrm{af}}$ & 1 & 0.7 & $4 \mathrm{t}_{\mathrm{af}}$ & $20 \%$ & 1 & 1 \\
2 & $\mathrm{t}_{\mathrm{af}}$ & $-\mathrm{t}_{\mathrm{af}}$ & 1 & 0.7 & $8 \mathrm{t}_{\mathrm{af}}$ & $60 \%$ & 2 & 2 \\
3 & $3 \mathrm{t}_{\mathrm{af}}$ & $+\mathrm{t}_{\mathrm{af}}$ & 1 & 0.9 & $4 \mathrm{t}_{\mathrm{af}}$ & $20 \%$ & 2 & 2 \\
4 & $3 \mathrm{t}_{\mathrm{af}}$ & $+\mathrm{t}_{\mathrm{af}}$ & 1 & 0.9 & $8 \mathrm{t}_{\mathrm{af}}$ & $60 \%$ & 1 & 1 \\
5 & $\mathrm{t}_{\mathrm{aff}}$ & $-\mathrm{t}_{\mathrm{af}}$ & 1 & 0.9 & $4 \mathrm{t}_{\mathrm{af}}$ & $20 \%$ & 1 & 1 \\
6 & $\mathrm{t}_{\mathrm{af}}$ & $-\mathrm{t}_{\mathrm{af}}$ & 1 & 0.9 & $8 \mathrm{t}_{\mathrm{af}}$ & $60 \%$ & 2 & 2 \\
7 & $3 \mathrm{t}_{\mathrm{af}}$ & $+\mathrm{t}_{\mathrm{af}}$ & 1 & 0.7 & $4 \mathrm{t}_{\mathrm{af}}$ & $20 \%$ & 2 & 2 \\
8 & $3 \mathrm{t}_{\mathrm{af}}$ & $+\mathrm{t}_{\mathrm{af}}$ & 1 & 0.7 & $8 \mathrm{t}_{\mathrm{af}}$ & $60 \%$ & 1 & 1 \\
9 & $\mathrm{t}_{\mathrm{af}}$ & $+\mathrm{t}_{\mathrm{af}}$ & 2 & 0.9 & $4 \mathrm{t}_{\mathrm{af}}$ & $60 \%$ & 2 & 1 \\
10 & $\mathrm{t}_{\mathrm{af}}$ & $+\mathrm{t}_{\mathrm{af}}$ & 2 & 0.9 & $8 \mathrm{t}_{\mathrm{af}}$ & $20 \%$ & 1 & 2 \\
11 & $3 \mathrm{t}_{\mathrm{af}}$ & $-\mathrm{t}_{\mathrm{af}}$ & 2 & 0.7 & $4 \mathrm{t}_{\mathrm{af}}$ & $60 \%$ & 1 & 1 \\
12 & $3 \mathrm{t}_{\mathrm{af}}$ & $-\mathrm{t}_{\mathrm{af}}$ & 2 & 0.7 & $8 \mathrm{t}_{\mathrm{af}}$ & $20 \%$ & 2 & 1 \\
13 & $\mathrm{t}_{\mathrm{af}}$ & $+\mathrm{t}_{\mathrm{af}}$ & 2 & 0.7 & $4 \mathrm{t}_{\mathrm{af}}$ & $60 \%$ & 2 & 2 \\
14 & $\mathrm{t}_{\mathrm{af}}$ & $+\mathrm{t}_{\mathrm{af}}$ & 2 & 0.7 & $8 \mathrm{t}_{\mathrm{af}}$ & $20 \%$ & 1 & 1 \\
15 & $3 \mathrm{t}_{\mathrm{af}}$ & $-\mathrm{t}_{\mathrm{af}}$ & 2 & 0.9 & $4 \mathrm{t}_{\mathrm{af}}$ & $60 \%$ & 1 & 2 \\
16 & $3 \mathrm{t}_{\mathrm{af}}$ & $-\mathrm{t}_{\mathrm{af}}$ & 2 & 0.9 & $8 \mathrm{t}_{\mathrm{af}}$ & $20 \%$ & 2 & 1 \\
\hline
\end{tabular}


Table 3 - Experimental and predicted specimen initial skin buckling and collapse loads.

\begin{tabular}{|c|c|c|c|}
\hline Specimen & $\begin{array}{l}\text { Experimental } \\
\text { results }\end{array}$ & $\begin{array}{l}\text { Simulation } \\
\text { prediction }\end{array}$ & $\begin{array}{l}\text { Modified static } \\
\text { strength design } \\
\text { method prediction }\end{array}$ \\
\hline $\begin{array}{c}\text { Initial skin } \\
\text { buckling }(\mathrm{kN})\end{array}$ & 89.7 & 91.0 & 86.3 \\
\hline $\begin{array}{c}\text { Specimen } \\
\text { collapse }(\mathrm{kN})\end{array}$ & 336.8 & 342.2 & 293.8 \\
\hline $\begin{array}{l}\text { Initial buckling } \\
\text { to collapse } \\
\text { ratio }(\%)\end{array}$ & 27 & 27 & 29 \\
\hline Collapse mode & $\begin{array}{l}\text { Combined stiffener } \\
\text { global flexure and } \\
\text { local free flange } \\
\text { instability }\end{array}$ & $\begin{array}{l}\text { Combined stiffener } \\
\text { global flexure and } \\
\text { local free flange } \\
\text { instability }\end{array}$ & $\begin{array}{l}\text { Combined stiffene } \\
\text { global flexure and } \\
\text { local free flange } \\
\text { instability }\end{array}$ \\
\hline
\end{tabular}



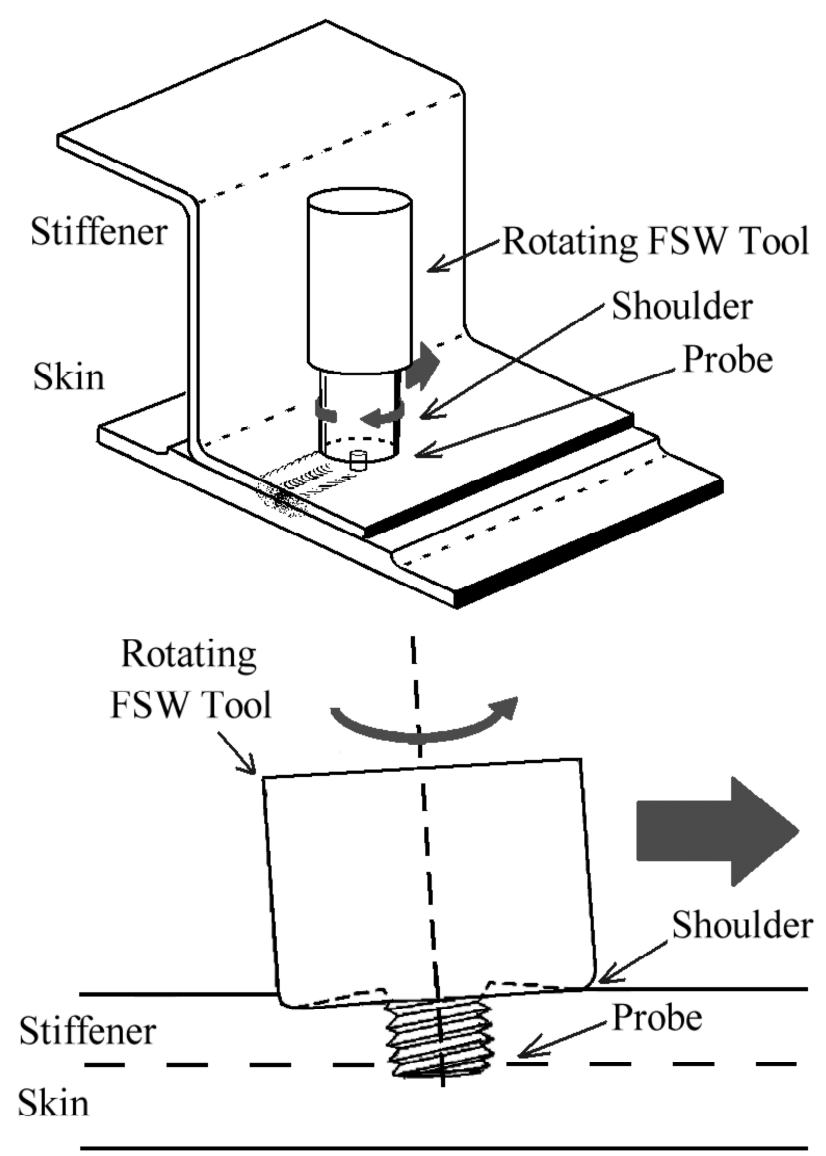

Figure 1-A Schematic of the lap joint welding process. 


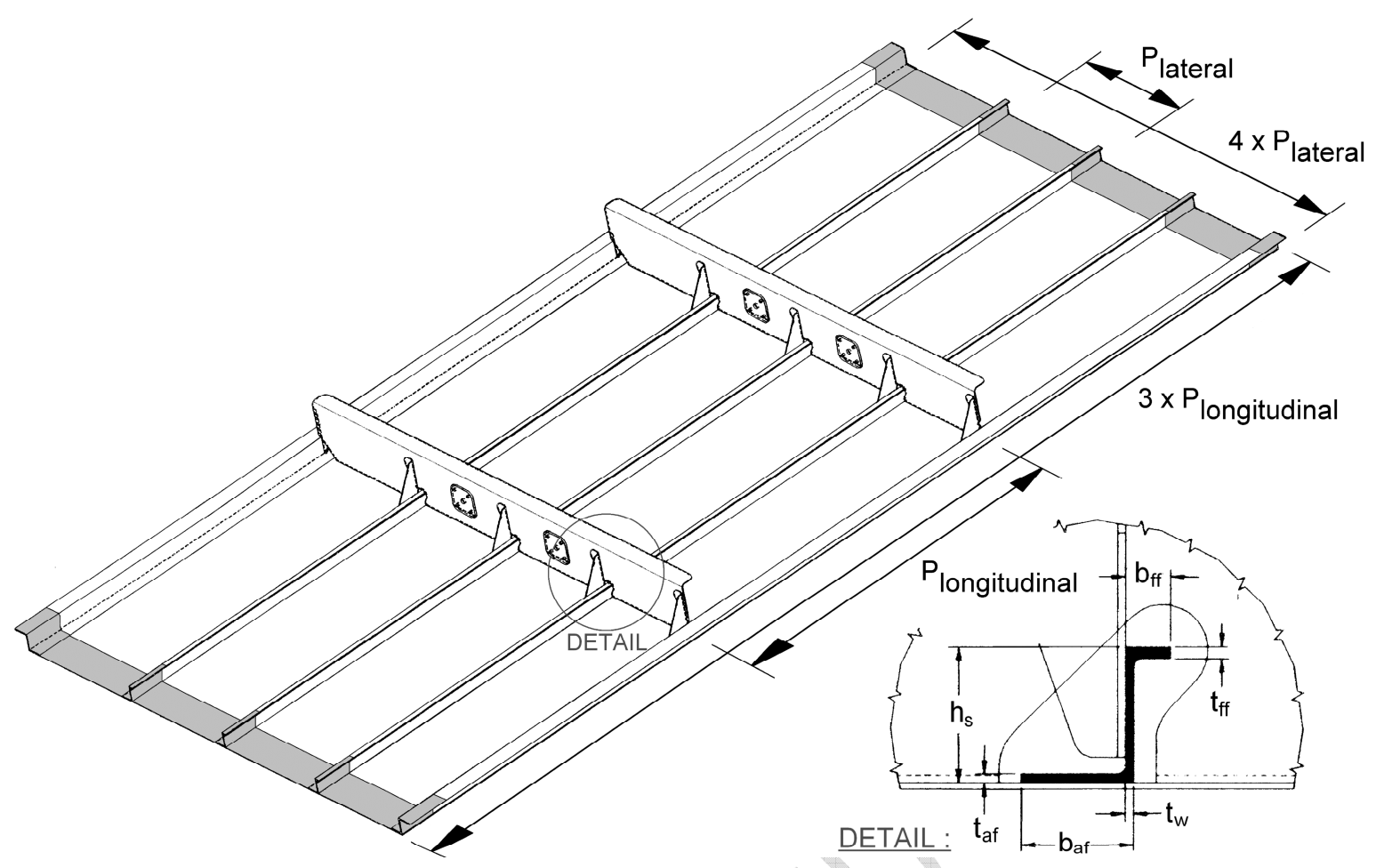

Figure 2 -Specimen design. 


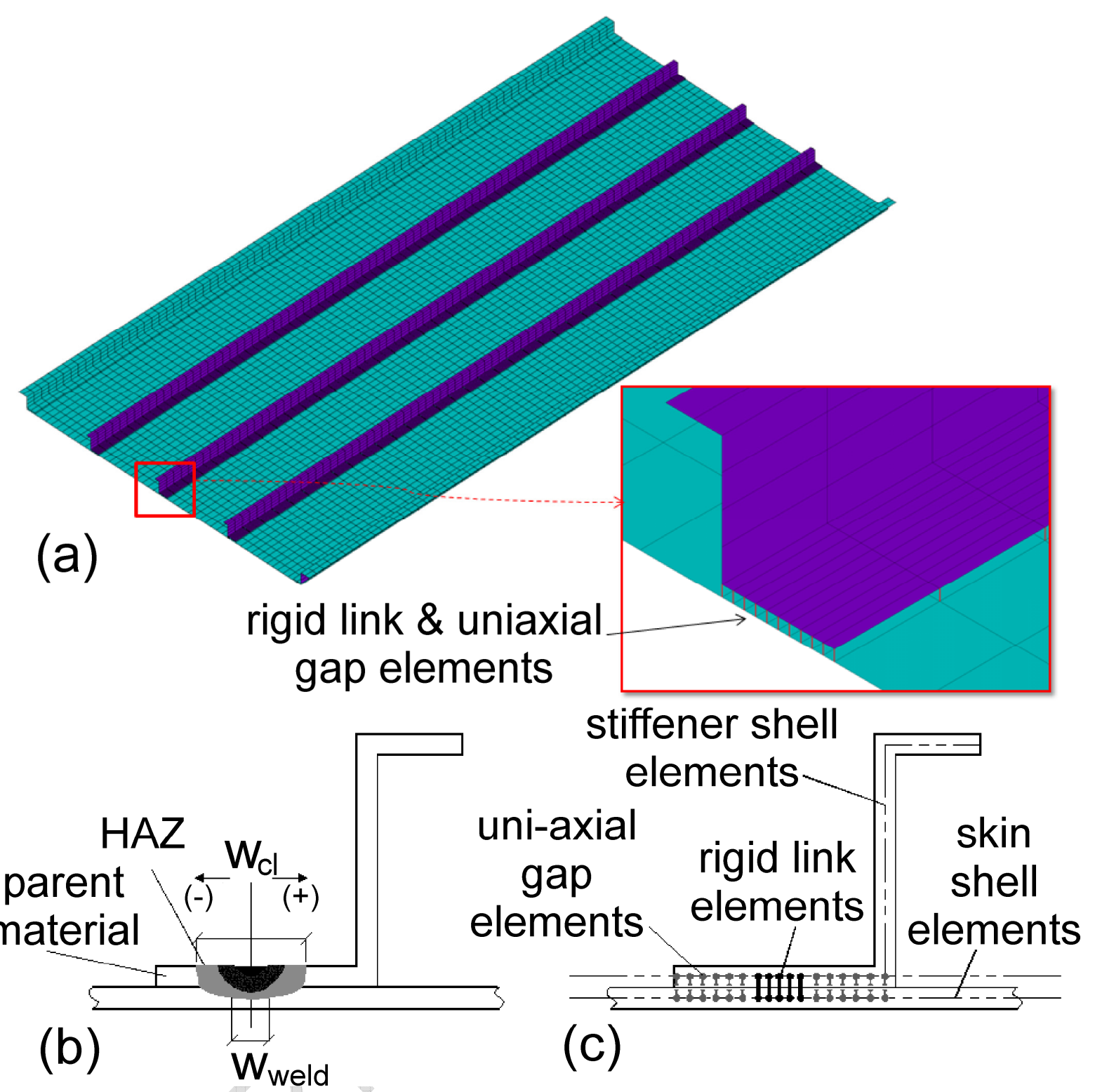

Figure 3 -Specimen mesh and skin-stringer joint idealisation. 

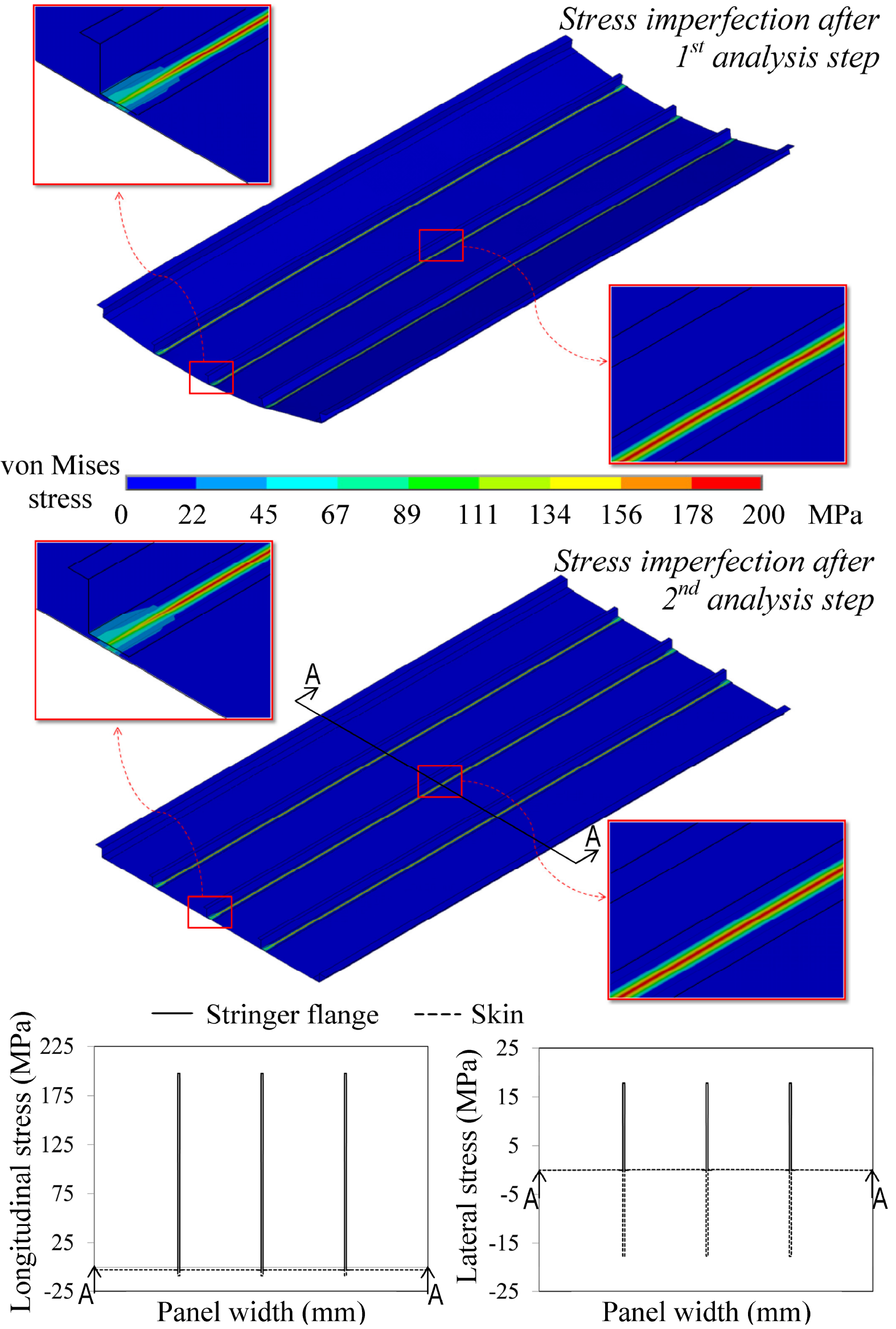

Figure 4 -Specimen initial stress imperfection. 

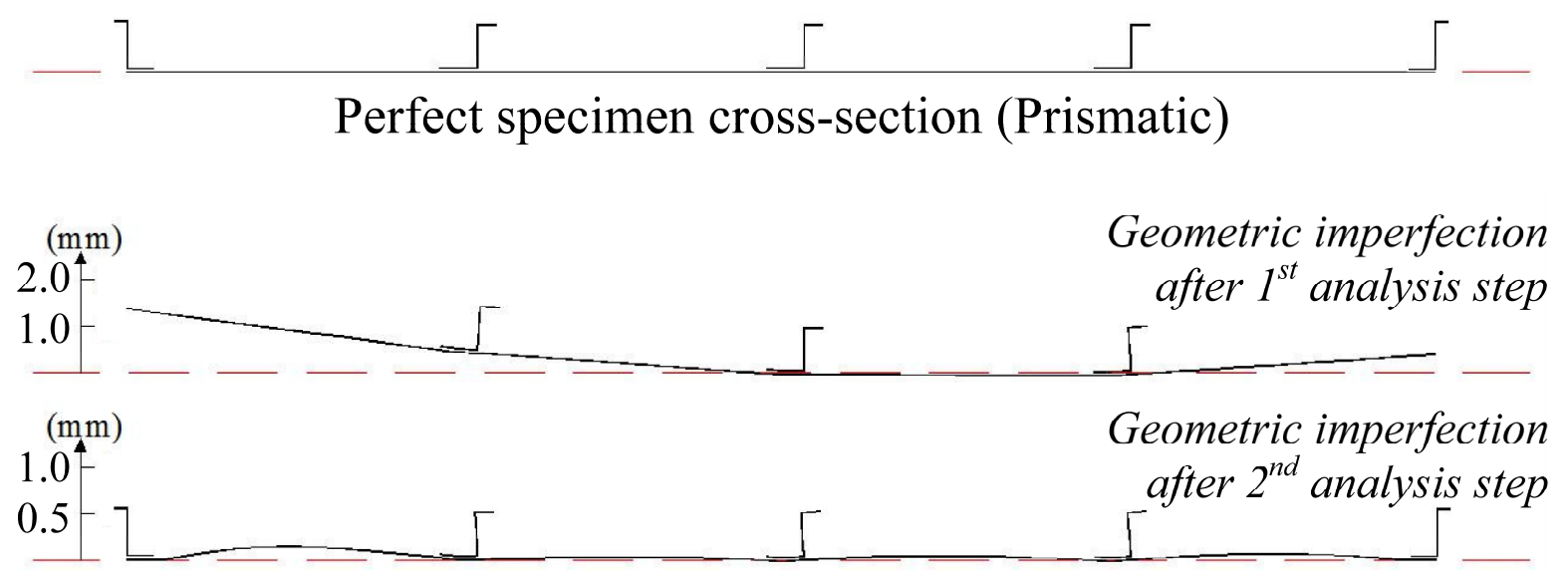

Cross-section at centerline of upper lateral bay

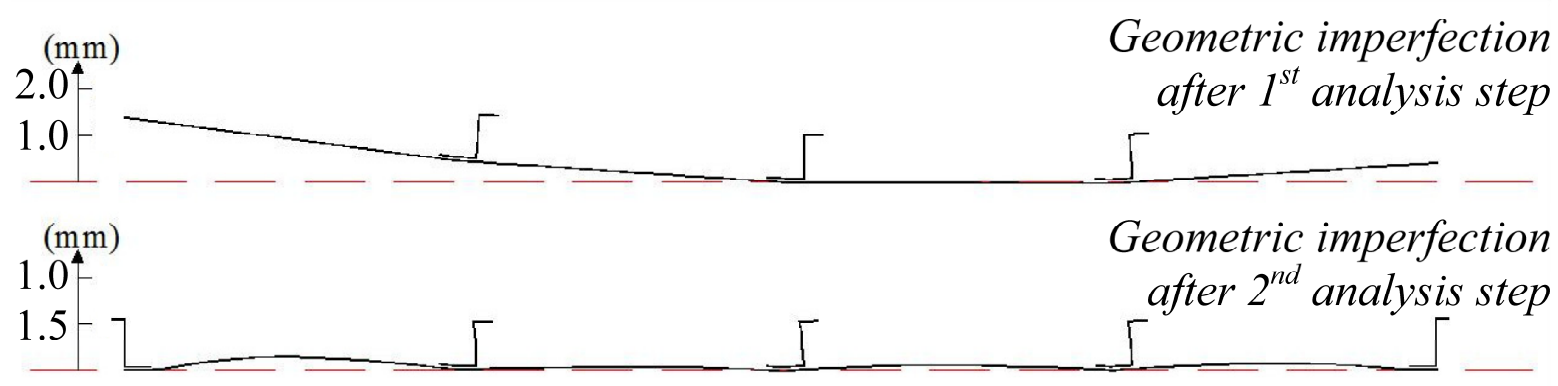

Cross-section at centerline of middle lateral bay

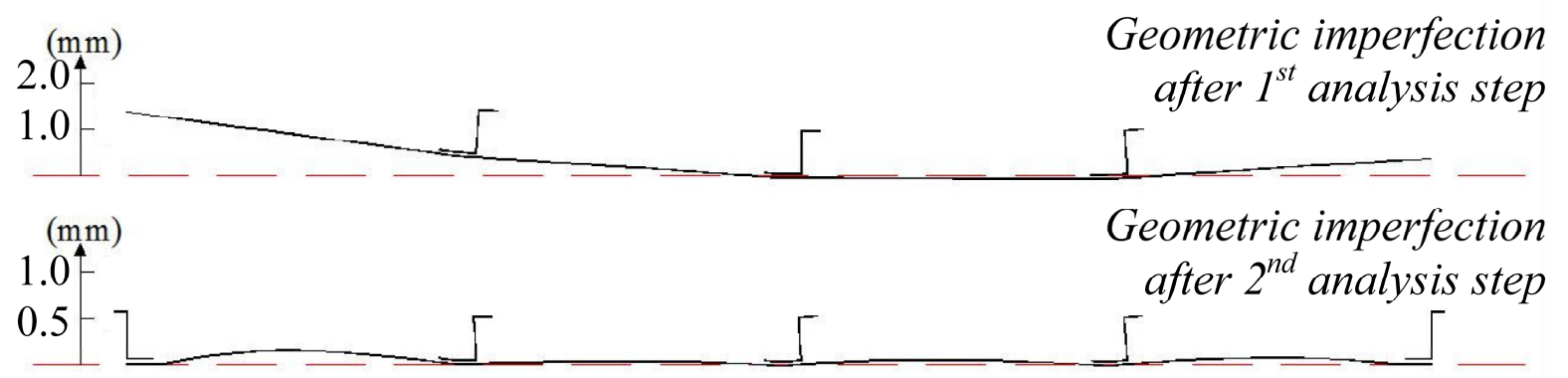

Cross-section at centerline of lower lateral bay

Figure 5-Specimen initial geometric imperfection. 

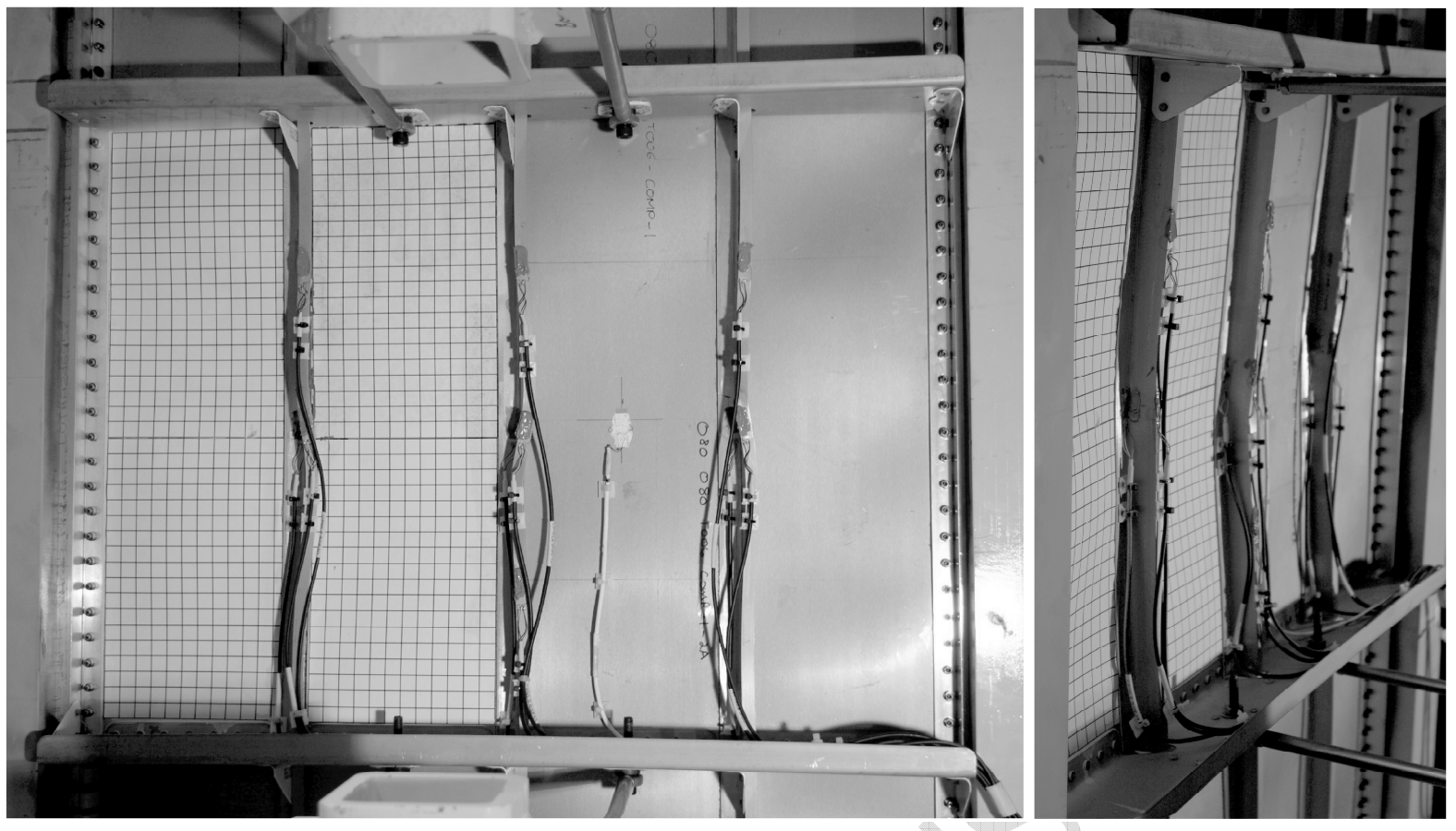

Figure 6 -Specimen ultimate collapse mode. 


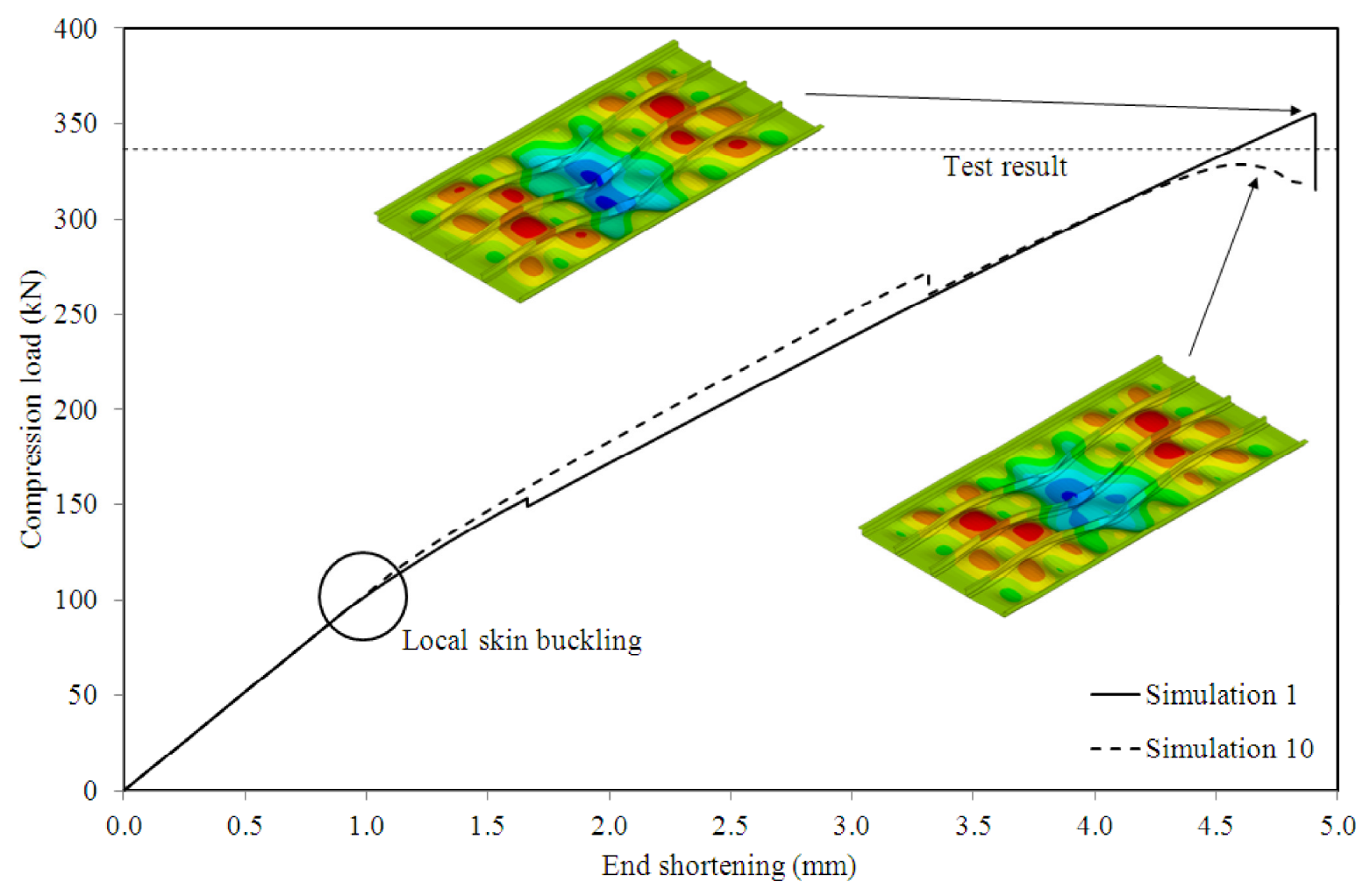

Figure 7 - Load versus end shortening curves and collapse modes for simulations 1 and 10 (collapse mode deformation magnified by a factor of five to improve visualisation). 


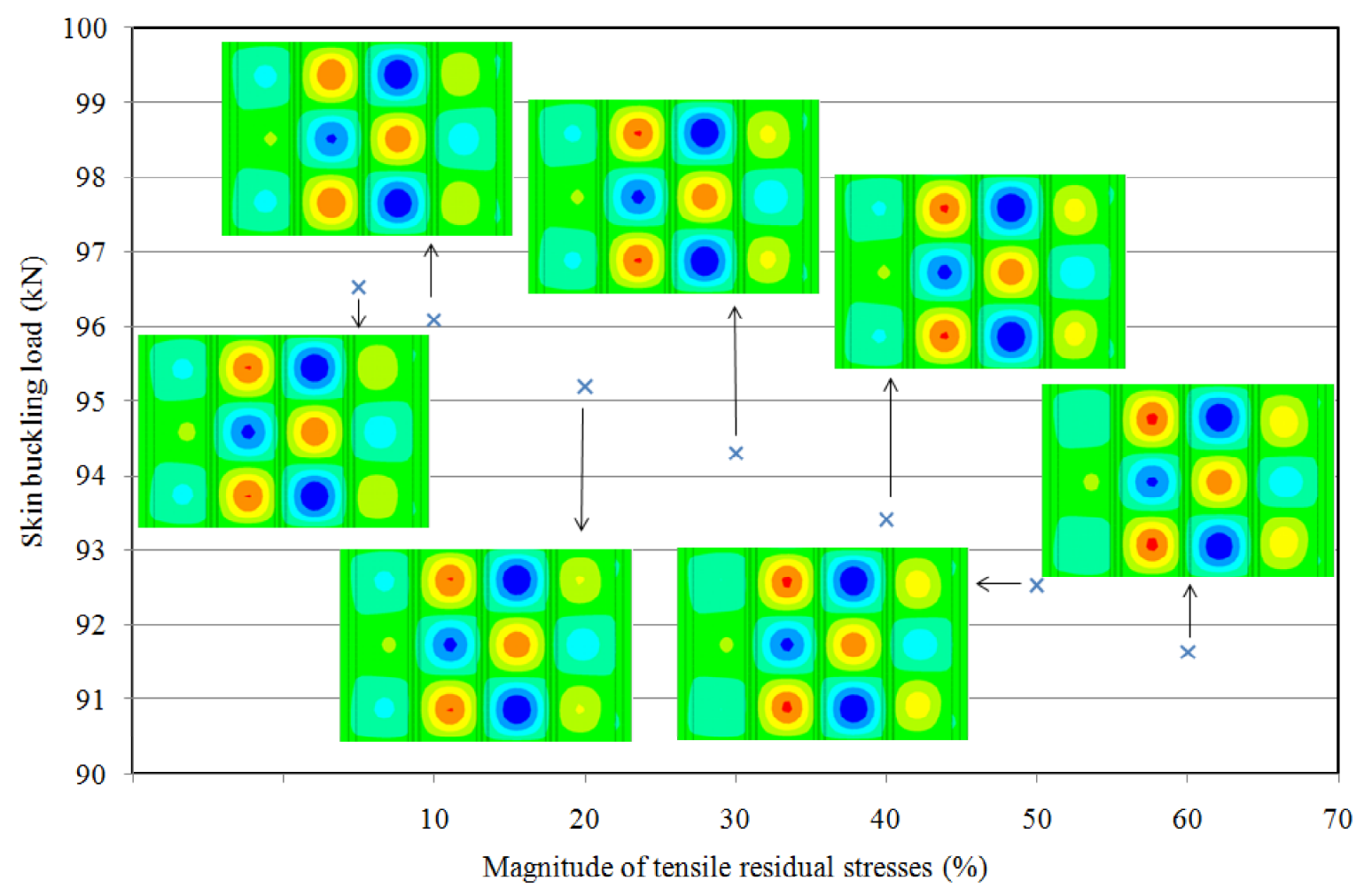

Figure 8 - Specimen initial skin buckling parametric analysis results (mode plots depict only the specimen middle skin bays). 


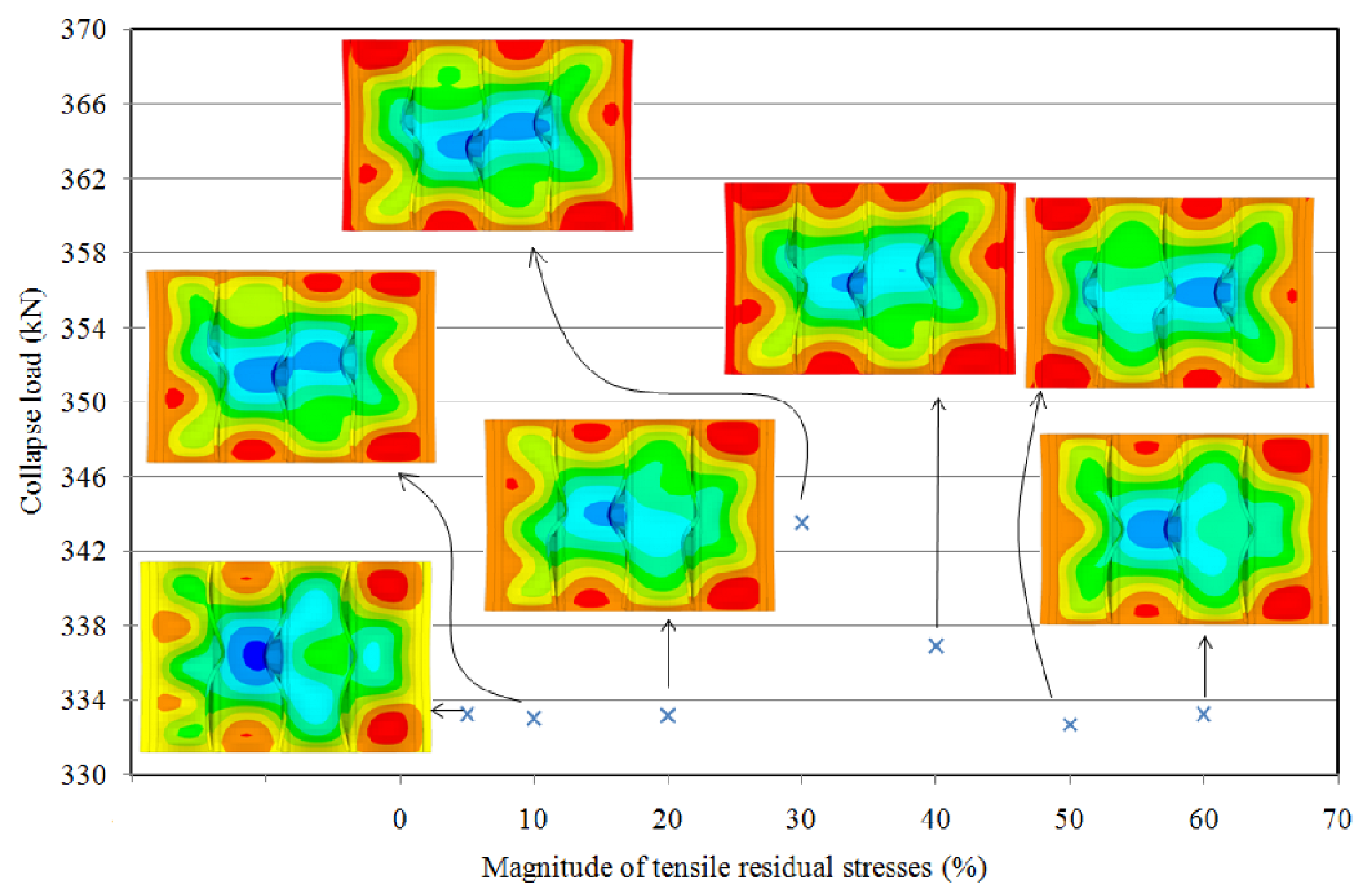

Figure 9 - Specimen collapse parametric analysis results (mode plots depict only the specimen middle skin bays, deformation magnified by a factor of five to improve visualisation). 